\title{
An ethical framework for psychiatry
}

\author{
SIDNEY BLOCH and STEPHEN A. GREEN
}

\begin{abstract}
Summary Psychiatry has not reached a consensus hitherto concerning an optimal theoretical framework for ethical decision-making and corresponding action. Various theories have been considered, but found wanting. Moreover, classic theories may contradict one another, contribute to confusion and immobilise the clinician. We have examined major theories commonly applied in bioethics, conferred with moral philosophers and psychiatrists and striven to apply more recent insights drawn from moral philosophy. We report that instead of pursuing a single theoretical

framework, we should garner the strengths of compatible approaches in a synergistic way. We propose a particular complementarity of principlism - with its pragmatic focus on respect for autonomy, beneficence, non-maleficence and justice - and care ethics, a variant of virtue theory, which highlights character traits pertinent to caring for vulnerable psychiatric patients.
\end{abstract}

\section{Declaration of interest None.}

'The use of force', a short story by William Carlos Williams (1984), vividly illustrates the multilayered ethical dimensions of medical practice. A country doctor is called by parents to attend their feverish daughter, whose condition is a cause for grave concern given the prevailing diphtheria epidemic. The child steadfastly resists the physician's efforts to examine her, even attacking him when he struggles to look down her throat. After appealing unsuccessfully to the parents to take responsibility for their child's intransigence, he launches a physical tussle with the girl, convinced he must make the diagnosis.
Despite recognising he had 'got beyond reason', the doctor persists, because 'The damned little brat must be protected against her own idiocy... [and] others must be protected against her' (p. 59). He forces her mouth open, sees 'both tonsils covered with membrane', and finally understands, 'She had fought valiantly to keep me from knowing her secret... [and] lying to her parents in order to escape just such an outcome as this' (p. 60).

Williams' poignant story raises fundamental concerns about the ethical dilemmas spawned by medical practice: What degree of paternalism may be adopted to promote a patient's well-being? Does protecting a child provide a more powerful justification to act paternalistically? How does the doctor resolve the unavoidable conflict of dual agency - serving the interests of the girl and of her parents? Is the doctor's primary responsibility always to the patient or can serving a broader community good override it?

Psychiatrists face similar ethical quandaries as their medical colleagues, and their response may have dire consequences for patients, their families and the general community. However, as the philosopher Jennifer Radden (2002) points out, issues intrinsic to mental healthcare - such as competence, self-harm, a threat of harm to others and involuntary treatment suggest that ethics for psychiatry differs from that 'provided by the principles of bioethics applicable to all fields of medicine' (p. 52); moreover, the interrelationship of three aspects of psychiatric treatment - the therapeutic alliance in which the actual relationship is at the heart of treatment, distinct features of the patient such as impaired reasoning and a feeling of stigma, and the goals of the professional interaction which can extend to substantial personality change - define its special place 'in terms of the ethical demands it places on practice' (p.52). Radden offers us a preliminary appraisal but leaves the task of substantively formulating psychiatry's 'unique ethic' to others.

We take up Radden's challenge, spurred by our shared experience that any single moral theory fails to address satisfactorily myriad moral dilemmas buffeting the work. Moreover, moral theories, in their application clinically, often confuse rather than clarify. Indeed, they may even contradict one another. Our aim is to review competing theories, note their strengths and limitations briefly, and offer a new framework and corresponding pragmatic guidelines, which we hope will meet the needs of those who have to grapple with the multifaceted ethical dilemmas inherent in the psychiatric encounter.

\section{IS THERE AN OPTIMAL ETHICAL FRAMEWORK FOR PSYCHIATRY?}

Ethical concerns about the psychiatrist's role and functions have dogged the profession for at least three centuries (Bloch $\&$ Pargiter, 2002). Moral harms have emerged from the misuse of the asylum as a custodial 'warehouse', misunderstanding of the transference relationship, the gruesome effects of physical treatments such as leucotomy and insulin coma (to name but two), the misuse of psychiatry for political purposes (as occurred in the former Soviet Union) and systems of healthcare that jeopardise the needs of the individual, purportedly to benefit the many. In our view, psychiatrists have no choice in the face of these profound ethical difficulties but to respond as moral agents.

The task, however, is complicated by the lack of a coherent framework for ethical decision-making, a conclusion buttressed by two observations. First, rationales and methods used to resolve ethical questions differ radically. Indeed, competing ethical theories may so contradict one another as to generate irreconcilable tensions for the clinician. Attempts to compromise may take the form of a checklist approach that filters the details of a case through various algorithms in an attempt to discern the best match; unfortunately, this process often leads to conflicting remedies. For example, one psychiatrist may conclude that the features of a case support respect for the patient's autonomy whereas his colleague reasons they justify a paternalistic role. Second, in the wake of contradictory ethical theories, psychiatrists 
may simply devalue the whole need for ethical reasoning and even act nihilistically. Frustrated by conflicting claims, practitioners may dispense with any attempt to bring reasoning to the situation and resort to personal preferences which may be illfounded.

We now turn to our attempt to avoid these unsatisfactory outcomes. First, we present a clinical scenario to illustrate the complex ethical decision-making required of the psychiatrist. We have been unable to obtain consent because the events described occurred over 25 years ago. We have therefore modified certain facts to prevent identification of the protagonists involved. We then consider theoretical options that have been variously deployed to deal with the relevant ethical issues involved. Arising out of this diversity of approaches we offer our ideas for an ethical framework that may best fulfil the specific requirements of the psychiatric encounter.

\section{JILL, TIM AND THE BABY}

A consultant psychiatrist Dr Jones was awakened in the early hours by a call from a family physician Dr Brown, who had been summoned a few hours earlier to a couple's home by the husband Tim. His 22-year-old wife jill had begun acting in a 'bizarre' manner, exhibiting restlessness, perplexity and remoteness from Tim, her in-laws (with whom they lived) and her 10-week-old baby. The family doctor had been summoned when jill began to visit several neighbours without any obvious purpose and had to be brought back home. Following his failure to clarify the cause of jill's actions, Dr Brown was wrestling with a specific question: should she be treated against her wishes given the risk of harm to herself and/or the baby.

Dr Jones arrived at the family home to find a reticent, detached woman complaining that 'They have been out to get me from the beginning' and alluding to 'world famine and starving children'. Mental status examination revealed a woman with paranoid ideas, denying suicidal and homicidal impulses, and not obviously delirious. Family members intimated that jill had withdrawn progressively 'into herself' since the baby's birth, at which time they had learned that she had had a brief extramarital affair 9 months earlier. The uncomfortable question of paternity loomed large, particularly as Tim may have been infertile owing to a rare endocrinological disorder. But he was adamant he had sired the child.

Jill trenchantly resisted Dr Jones' recommendation that she be hospitalised since she did not want to leave her baby under any circumstances. Tim supported her in this. He did not regard his wife as mentally ill and feared she would deteriorate if placed alongside genuinely disturbed patients. Their unified position carried considerable force given Dr Jones' inability to offer the family a definitive diagnosis. He responded by observing that jill was clearly not her usual self, there was concern for her safety as well as for that of the child (given the elevated risk of infanticide in post-partum psychotic conditions), and Tim was evidently overwhelmed by the prevailing circumstances.

The couple's adamant reluctance to agree to admission to hospital required $\mathrm{Dr}$ Jones to explore competing ethical values inherent in the clinical situation. Did he owe a primary allegiance to jill, to the helpless baby who had no autonomous voice or to Tim, who seemed quite unable to cope with the ambiguity and potential risks of his wife's behaviour? The dilemma called for a judgement that balanced protecting the life and promoting the well-being of an identified patient versus meeting the crucial interests of the other protagonists in the drama. Dr Jones was also obliged to weigh up respect for Jill's right to selfdetermination versus promoting her welfare even if it necessitated curtailing her freedom, albeit temporarily. As a practitioner he would presumably conduct a detailed risk assessment and be influenced by a corresponding duty of care. In our view, this makes sound clinical sense but does not provide a sufficient framework to do justice to the intrinsic complex ethical issues.

\section{SURVEYING COMPETING ETHICALTHEORIES}

Had Dr Jones consulted a textbook on ethical theory to guide his moral reasoning and subsequent clinical judgements, he would have been confronted with several approaches to ethical decision-making, each of whose proponents tends to advocate for its primacy. All the theories consist of a comprehensive formulation of presumed moral judgements (e.g. do not kill), with guidelines indicating how those judgements might apply to a given set of circumstances (e.g. a terminally ill patient with intractable pain). Our first step in proposing a distinctive ethical framework for psychiatry is to review these approaches, including mention of their strengths and limitations. We focus on deontology (Kant, edition 1983), utilitarianism (Mill, edition 2001), principlism (Beauchamp \& Childress, 2001), virtue theory (Aristotle, edition 1985 ) and the ethics of care (Baier, 1985, 2004) since these have been widely supported by influential commentators and thus warrant our attention. We have excluded a model based on case precedent, on the grounds that it is theoretically limited and has little contemporary support.

\section{Kantianism}

Deontological theory, derived from the arguments of the German moral philosopher Immanuel Kant (edition 1983), is grounded in duty, holding that the right moral action is justified by a person's intrinsic values: we do the right thing (e.g. telling the truth) because we have a moral obligation to do so, not because of an extrinsic motivation (e.g. lying could lead to bad consequences). The sole basis for establishing moral rules is rational argument, which yields universally applicable 'categorical imperatives'; acting in terms of these imperatives qualifies a person as having 'good will'.

An appeal of deontological theory is the seeming clarity and consistency it brings to moral deliberation. Once set, a categorical imperative is binding, and its practical application is similarly adhered to. The drawback of this 'absolutist' feature is that nuanced judgements required in particular situations are not feasible, as illustrated by our clinical vignette. We could argue that respect for autonomy is a primary duty to an adult like Jill about which we should not waver; treating her with 'moral dignity' is the categorical imperative. The snag, however, in such an absolute framework is the risk of grave consequences for the baby, for Tim and even Jill herself. We may also note how Kantianism makes it difficult to resolve conflicting obligations. If it is always a duty to respect autonomy and always a duty to protect a person from self-harm, the psychiatrist is immobilised, denied an available remedy. Truth-telling is another commonly agreed upon duty in clinical practice. Does this mean that we should unswervingly inform Tim that he is not the father of the baby and should we confirm this suspicion with DNA testing?

\section{Utilitarianism}

Does J. S. Mill's (edition 2001) utilitarian theory serve us better in cases like that of Tim and Jill? Its basic tenet holds that an act is morally right if, when compared with alternative acts, it yields the greatest possible balance of good consequences or the least possible balance of bad consequences - the principle of utility. In contrast to Kantianism, the intrinsic value of an act is morally irrelevant since right and wrong conduct depends on outcome. For example, a law that minimally benefits the many but severely deprives the few is morally right because, on balance, it maximises human welfare. 
The many criticisms levelled against utilitarianism are well illustrated by our case. First, it is exceedingly difficult to calculate accurately the benefits and risks associated with either compulsory or non-compulsory treatment for Jill. Clinicians would likely apply various criteria in making this determination. For instance, they might well disagree on the nature of potential harm resulting from either respecting or curtailing Jill's autonomy. Second, beyond the task of determining what constitutes benefit and risk, utilitarianism demands impartiality. Each calculation must be unfettered by bias and afford equal attention to the preferences of every person or group affected. We have only to imagine how in the vignette a tense atmosphere might have prevented genuine objective decision-making. Third, maximising the ratio of benefit to harm may compel a clinician to act in ways inconsistent with personal belief, thereby undermining one's sense of integrity. The issue is illustrated by managed-care policies that promote the time-efficient intervention of drug treatment at the expense of psychotherapy, despite the psychiatrist's recognition of a sound clinical indication for the latter.

\section{Principle-based ethics}

Principle-based ethics or principlism, as it has been called in recent years, was introduced by Beauchamp \& Childress (2001) in the 1970s in an attempt to reconcile the divergence between utilitarian and deontological models by linking moral decision-making to 'mid-level' principles subject to change (e.g. in light of new scientific findings) rather than to universal rules. This is in the tradition of philosophical pragmatism as enunciated by William James (1955). Principlism posits that widely held principles, too general in quality to address the particulars of diverse circumstances, at least provide a starting point for moral judgement. In tandem with other guiding information, such as relevant empirical data or consistent clinical observations, the framework offers an approach to moral deliberation that adheres to commonly agreed upon rules but permits flexibility in interpreting their intent. By embracing tenets of both utilitarian and deontological theories, principlism can lay claim to a broadly based foundation. In addition it proposes specific guidelines for ethical dilemmas, which obviates the complexities of deriving a categorical imperative from pure reasoning or invoking the principle of utility for a particular clinical situation. For all these reasons principlism has gained pre-eminent status in bioethics, with widespread application of its quartet of principles - nonmaleficence (first do no harm), beneficence (acting to benefit others), respect for autonomy (acting to acknowledge a person's right to 'self-government') and justice (treating people fairly).

A key criticism of principlism concerns methodology. Although it does proffer guidelines for ethical deliberation, the approach is far from definitive. Revisiting the work of W. D. Ross (1930) will enable us to examine the limitations of principlism. This British moral philosopher proposed in 1930 in The Right and The Good that moral reasoning often requires a judgement about competing obligations in order to establish the most compelling balance of right over wrong. To accomplish this task, Ross introduced the concept of prima facie duty - one that is right and binding, all other things being equal. Prima facie obligations are therefore not absolute but respond to circumstance. For example, lying to a patient is prima facie wrong unless the clinician believes moral weight should be given to protecting the patient from distress through withholding the truth (e.g. an elderly, frail person is informed that she has a growth rather than metastatic cancer). In the situation of two competing prima facie obligations, ethical reasoning determines actual duty, the prima facie obligation considered most binding. In the context of our case vignette, respecting Jill's autonomy and protecting her baby's welfare are conflicting prima facie obligations. The obvious predicament in discerning which of the pair should constitute the actual duty highlights how the value of Ross's method, and in turn principlism, is based in pragmatism. Given this way of working, the difficulty is that moral reasoning falls between the poles of subjectivity and objectivity.

\section{Virtue theory}

Virtue theory, an alternative framework for ethical deliberation, avoids the pitfalls of rules and principles altogether. The prototype is most closely identified with Aristotle (edition 1985), who avowed that a person's character is at the heart of moral deliberation. The prerequisite to living an ethical life is developing character traits that promote virtuous behaviour; this, in turn, advances the common good. Artistotle's catalogue of virtues, reflecting his conception of proper conduct, ranges from magnanimity, agreeableness and friendship to scientific knowledge, prudence, technical skill and wisdom.

Aristotelian theory is teleological in that it is concerned with achieving the good towards which things move. To strive for telos (the Greek word for end) is to pursue virtue. The end towards which human beings move is intelligence, and pursuit of reason is the most elevated virtue. Such intellectual wisdom is paralleled by phron$\bar{e}$ sis, practical wisdom, which results from habit and training. Study and experience inform people about which ends should be defined as good, whereas phronesis is achieved by pursuing those ends continually. The virtuous person thus cultivates such right motives as honesty, courage, faithfulness, integrity and trustworthiness in order to follow the correct course in particular situations.

Criticism of virtue theory centres around the requirement that it be linked to a disposition to do good habitually. Although articulating the nature of that good has spanned centuries of philosophical debate, a consensus about which attributes are essential for a person to become virtuous remains elusive. This elusiveness might prompt some to advocate for minimum guidelines of the good, but this would blur the boundary between virtue and rule-based theories such as Kantianism or utilitarianism.

Another objection to virtue theory is reflected in the Platonic dialogue between Socrates and Meno (Plato, edition 1991), which poses the question of whether virtue can be taught and honed through practice or whether it is a natural disposition. The question remains unanswered. Pellegrino (1985) describes virtue as 'a character trait, an internal disposition, habitually to seek moral perfection, to live one's life in accord with the moral law, and to attain balance between noble intention and just action' (p.243). Alas, the definition leaves unanswered the question of whether every person has that innate capacity. The psychoanalytic view that holds that pursuit of an 'ego ideal' may facilitate virtuous behaviour certainly does not guarantee its realisation. Whether one needs a core nature to cultivate virtue remains an open question and one that 
has implications for the applicability of virtue theory.

The argument could be made that if Drs Jones and Brown are virtuous persons, or at least strive to be, their moral agency would encompass only those acts that are socially valuable. They would therefore wish to respond sensitively and trustworthily to the people for whom they are professionally responsible. This may seem straightforward but there is a fly in the ointment. Which character traits should they rely on in the clinically ambiguous circumstances in which they find themselves and how should they apply them so that they will be of value to everyone involved? No matter how compassionate and conscientious certainly two prima facie traits desirable in the situation - the interests and needs of patient, spouse, baby, grandparents and community may not all be satisfied. In summary, virtue theory cannot, in and of itself, guide clinicians to deal with the moral complexity facing them.

\section{Ethics of care}

The ethics of care is a contemporary variant of virtue theory that draws also on feminism and psychological constructs, particularly the role of emotion in moral deliberation. The blend affords primacy to character and interpersonal relationships over rules. Decision-making is thus grounded in the core value of humankind's capacity to extend care to people who are in need or vulnerable. The ethics of care approach promotes sensitivity to the 'moral' emotions - compassion, friendship, love and trustworthiness - since the interpersonal dimension of moral conduct turns on psychological features. The conventional family serves as the model for moral behaviour. For example, fidelity is interpreted as the type of feeling held by a parent towards her child in contrast to a more impersonal attachment between a professional and patient. In the clinical sphere we may illustrate this by empathising with patients' emotions in order to understand more clearly their fears, wishes and needs, and then shaping treatment according to a unique life narrative.

The feminist aspect of care ethics reflects Carol Gilligan's (1982) observations of interactional patterns among children. Girls place much greater store on emotions engendered in play than boys, who are more inclined to relate to one another following set guidelines. This gender difference, Gilligan argues, pertains to moral development and is central to an account of care ethics. Care ethics draws heavily on Aristotelian theory in calling for the cultivation of virtuous traits such as sympathy, compassion and patience, in order to promote desirable ethical behaviour. Nevertheless it rejects the notion that a universal guideline can be found behind every moral intuition (Baier, 1985).

Moreover, the approach objects to theories that encompass a system of principles, arguing that none can claim primacy in a pluralistic society characterised by diverse moral traditions. Universal moral rules are eschewed as abstractions, detached from the real world. For example, reasoning to discern moral guidelines is rejected in that it views the world as atomistic, comprising detached human beings; the interpersonal dimension of moral life is thus ignored. Care ethics views utilitarian impartiality and the deontological stress on respect for autonomy as derivatives of perceptions that misrepresent actual relationships between people who are wrestling with day-to-day moral questions.

A criticism that could be levelled at care ethics (as at principlism) is that it is intrinsically a method, not a conceptually shaped theory. Therefore, any benefit that may derive from a pragmatic approach to clinical situations is open to the charge of subjectivity. Moral rules may be faulted for their constrictiveness but their absence may permit a relativism that undermines claims of reasoned ethical debate. Cultural diversity and the range of perspectives on emotional awareness and expression that typify many contemporary communities may well contribute to inconsistent, even contradictory, appraisal of moral questions.

\section{DISCUSSION}

There is widespread support for a role for rules to define the ethical practice of psychiatry. For instance, the American Psychiatric Association's (APA's) Principles of Medical Ethics with Annotations Especially Applicable to Psychiatry, a carefully articulated explication of seven broad principles, has been applied regularly to that end since 1973 (current edition: American Psychiatric Association, 2001). Similarly, the 11 principles, each with detailed annotations, of the third edition Royal Australian and New Zealand College of Psychiatrists' Code of Ethics (2004) have guided the moral deliberations of its Fellows and trainees. One of us (S.A.G.) can attest to the practical utility of annotated principles in the adjudication of cases brought before ethics committees of the APA. However, the process also highlights the limitations of a rule-based approach. First, in many cases finely tuned interpretations of one or more principles are required. The subtlety of the distinction between a boundary crossing and a boundary violation of the therapeutic relationship illustrates readily how application of ethical guidelines can be problematic (Gutheil \& Gabbard, 1993). Second, a rule-driven schema brings into question the comparative value of the classic deontological and utilitarian perspectives, an exercise that heightens scepticism about the soundness of either. Finally, rule-bound ethics neglects the core issue of clinicians whom Kant would deem not to be of good will, namely those who conform to ethical guidelines solely to avoid an adverse outcome and thus as a form of self-protection. Can we deem their work as ethical even if patients do not suffer negative consequences?

These drawbacks prompt Pellegrino (1985) to fault rules of ethical conduct as too remote from the psychological context in which moral decisions are made. $\mathrm{He}$ therefore espouses an Aristotelian perspective, grounded in the person of the virtuous doctor who is inclined to promote his patient's interests and hold them above his own. Virtue theory has a particular appeal to psychiatry given the latter's emphasis on relationships in moral deliberation and, in turn, the salience of emotions. Morality is, after all, centred on what transpires between people, a reality that may well be overlooked when rules predominate. A virtue-driven approach, for instance, helps to minimise counterintuitive results that may emerge from the absolutist deployment of a moral obligation that could lead to wrongful action such as never lying, even to an assassin enquiring as to the whereabouts of his intended victim. On the other hand, virtue theory can be criticised for its elusiveness in defining the good to which one should aspire. Lacking objective criteria of that good, clinicians may be so influenced, wittingly or unwittingly, by their own values as to arrive at idiosyncratic judgements. What may ensue is a degree of undermining of the cohesion of the medical profession that arguably undercuts the value of any theory driven by virtue. 


\section{A potential remedy}

An ethical framework for psychiatry should, in our view, address the shortcomings of both rule- and character-based ethics, as outlined above, by proffering objective guidelines as well as flexibility in the face of unique clinical circumstances. We support the view that ethical deliberation has to encompass the pursuit of features that constitute moral action as well as traits of character that are morally praiseworthy (Veatch, 1998).

A potential way forward in bridging rule- and character-based theories has its provenance in the work of the Scottish philosopher David Hume (edition 1983). A key Humean premise is that ethical behaviour derives primarily from sentiment, not reason. The natural motivation of human beings is to act benevolently, although this inclination is constrained by societal circumstances (e.g. scarce resources). This prompts a need to establish rules of justice. Moral guidelines therefore derive from matters of the heart that are eventually adopted as societal norms. Reason enables us to understand an ethical dilemma but sentiment determines what is fair and unfair. In this way Humean theory allows for a balance between rule- and character-based theories by granting significance to 'moral' emotions which are then applied to derive or modify moral rules.

Care ethics, as articulated by the New Zealand philosopher, Annette Baier (1985) and to which we alluded in the section on ethics of care, is a contemporary framework that derives from Hume. Interpersonal relating is a cardinal aspect of ethical decision-making. The associated psychological dimension - the Humean notion of 'heart' as expressed in the capacity to extend care to others - is placed at the centre of ethical thinking. Baier's formulations highlight the influence of passion in the ethical sphere. Moral and psychological development are intimately bound together, as emotional sensitivity 'positively reinforces our responses to the good of cooperation, trust, mutual aid, friendship and love, as well as regulating responses to the risk of evil'.

Trust emerges as paramount in Baier's schema, particularly in its relation to vulnerability. This suits the psychiatrist well. The gist of her argument revolves around the idea that 'There, but for the grace of God, go I'. This 'mutual vulnerability' is ever present. An appropriate moral attitude in response is to contribute to a 'climate of trust' in our relationships with others. Promoting trust is complemented by other virtues such as acting thoughtfully, being considerate, willing to listen and not forcing one's views on others. This is akin to doing to others as we would have them do to us if roles were reversed. Other qualities that enhance the promoting of a climate of trust include patience, tact, honesty and discretion.

In adding to the list of virtues, the risk mounts that we are straying from an ethics of care and stumbling onto the terrain of virtue theory. Baier (2004: pp.184-185) is clearly sensitive to this possibility when she reiterates on several occasions that our effort to improve a climate of trust is the primary moral activity, the 'one vital component'. The related virtues mentioned above then become 'more than a mere bundle', even attain a 'loose unity', a 'little structure'. At the same time, the exercise of creating such a structure is never completed - 'there is always something more to be said'.

Does Baier's care ethic centred on trust, as just outlined, better serve the psychiatrist who grapples with moral dilemmas than the classical theoretical approaches? We would argue that her approach does in fact help but not on its own. Instead, it needs to be complemented by a more structured framework that allows the psychiatrist to resort to a set of guiding principles. We would argue that principlism fulfils this requirement most appropriately because it is inherently flexible and pragmatic. We attempt to demonstrate this with our original clinical scenario.

\section{Returning to Jill, Tim and the baby}

Dr Jones has entered a home where the atmosphere is tense and uncertain. The first step he needs to take is to convey a sense of consolation and comfort. Jill, Tim and Tim's parents are all, in their own ways, distressed and baffled. As for the baby, one can but try to imagine her insecurity. A character-based approach is called for, with Dr Jones challenged to bring to the vulnerable group compassion and sensitivity. In Baier's language, he needs to extend care to the group.

In one sense this parallels what he is already equipped to do through his continuing development of psychotherapeutic skills, the most pivotal of which is likely to be the capacity to respond empathically.
On the other hand, Dr Jones cannot realistically be regarded as having mastered a comprehensive catalogue of lofty virtues. Nothing extraordinary is required of him: he does not need to show Homeric courage or Aristotelian magnanimity or Platonic contemplative prowess or Maimonidean humility. Instead, what is called for is a willingness to empathise with the feelings of the anguished parties and the effort to imagine what each of them is experiencing, part of the virtuous process of contributing to a climate of trust.

Since care ethics regards the family as the primary 'institution' wherein moral education is accomplished and members may consider their own and others' moral claims, adhering to Baier's position embodies a regard for communal interests (those of Jill, Tim, Tim's parents, the baby, neighbours, family doctor and community at large in our case). Understanding their circumstances is likely to be enhanced through a Baierian perspective but not necessarily with the level of clarity required to reach reasoned moral judgements. At this juncture, the framework of principle ethics usefully complements care ethics. Any one of the four principles highlighted by Beauchamp \& Childress (2001) may warrant deliberation. The most incontrovertible of the quartet is non-maleficence. Whatever $\mathrm{Dr}$ Jones's final determination, he will strenuously avoid causing harm to any of the five people who depend on his judgement. Justice, another principle, is also uppermost in his mind since he is cognisant of the need to treat everyone fairly and equally (unless it emerges that someone, perhaps the helpless baby, has a claim to unequal attention).

When it comes to the remaining two principles, respect for autonomy and beneficence, Dr Jones will be substantially more challenged since he may not be able to appraise readily the capacity of Jill (and perhaps Tim) to act in a self-governing way. Care ethics will assist only in part, albeit significantly. Having imagined what each person is going through, Dr Jones will in all likelihood be sensitive to their needs in the immediacy of the moment and be aware of the potential repercussions of their vulnerability should these not be addressed. However, a diligent determination of the competence of the protagonists needs the principlism perspective.

Let us illustrate this interplay of care and principle ethics in relation to Jill. The young mother is buffeted by frightening internal forces ('They have been out to get 
me from the beginning'; 'world famine and starving children'). Withdrawal since her baby's birth, perplexity, remoteness from her husband and bizarre behaviour in relation to the neighbours are other clinical features which point to the question of whether or not she is competent to appreciate her circumstances and to cope reasonably. Above all, is she able to protect her vulnerable infant? Extending care to what is obviously a deeply distressed woman, who has lost her psychological anchorage, directs Dr Jones to the serious option of acting paternalistically, in accordance with the principle of beneficence. Whether this means urging Jill to agree to hospital admission, committing her to involuntary treatment or making arrangements for her and the baby to be closely supervised in the home until a comprehensive review becomes feasible remains an open question. However, what is clear is the requirement for Dr Jones to adopt a beneficent position in order that Jill does benefit (and at the same time, is not harmed in any way).

A degree of uncertainty prevails as we entertain Dr Jones's potential responses to Jill but we regard this as advantageous. Unlike Kantianism with its constraint of absolutism, or utilitarianism with its pressure to opt for a specific intervention on the uncertain premise that this will have a specific outcome, care and principle ethics together provide the means to reflect iteratively on what constitutes the most apt ethical action.

\section{Conclusions}

We have argued for the application of a particular ethical framework in relation to moral dilemmas encountered in psychiatric practice and illustrated this with the story of Jill and her family. Care ethics and

SIDNEY BLOCH, MD, PhD, Department of Psychiatry, University of Melbourne, Australia; STEPHEN A. GREEN, MD, MA, Department of Psychiatry, Georgetown University School of Medicine, Washington, District of Columbia, USA

Correspondence: Professor Sidney Bloch, Department of Psychiatry, University of Melbourne, St Vincent's Hospital, Melbourne, Australia 3065. E-mail: s.bloch@unimelb.edu.au

(First received 14 October 2004, final revision 7 April 2005, accepted I3 April 2005)

principlism are brought together to attain a complementarity, based on conceptual compatibility and synergy. The former calls for the cultivation of selective character traits, namely those intrinsic to extending care. The clinician is, however, not obliged to perch on an elevated moral pedestal. The latter serves as a flexible framework in which the contradictions of Kantianism and utilitarianism are obviated and the opportunity is provided to examine the 'ethical nuts and bolts' of the clinical context through sound moral reasoning.

\section{ACKNOWLEDGEMENTS}

We thank Cris Mileshkin, Helen Herrman, Michael Salzberg, Tom Beauchamp, Bob Veatch and Annette Baier for their critical reading of an earlier draft.

\section{REFERENCES}

American Psychiatric Association (2001) Principles of Medical Ethics: With Annotations Especially Applicable to Psychiatry, 200I Edition. Washington, DC: American Psychiatric Association.

Aristotle (edition 1985) Nicomachean Ethics. Indianapolis, IN: Hackett.

Baier, A. (1985) Postures of the Mind. Minnesota, MN: University of Minnesota Press.

Baier, A. (2004) Demoralization, trust and the virtues. In Setting the Moral Compass (ed. C. Calhoun), pp. 176-188. New York: Oxford University Press.

Beauchamp, T. \& Childress, J. (200I) Principles of Biomedical Ethics (5th edn). New York: Oxford University Press.
Bloch, S. \& Pargiter, R. (2002) A history of psychiatric ethics. Psychiatric Clinics of North America, 25, 509-524.

Gilligan, C. (1982) In a Different Voice. Cambridge, MA: Harvard University Press.

Gutheil, T. H. \& Gabbard, G. O. (1993) The concept of boundaries in clinical practice: theoretical and riskmanagement dimensions. American Journal of Psychiatry, I50, $188-196$.

Hume, D. (edition 1983) An Enquiry Concerning the Principles of Morals. Indianapolis, IN: Hackett.

James, W. (1955) Pragmatism. In The Age of Analysis (ed. M.White), pp. 160-173. New York: Mentor Books.

Kant, I. (edition 1983) Grounding for the Metaphysics of Morals. Indianapolis, IN: Hackett.

Mill, J. S. (edition 200I) Utilitarianism (2nd edn). Indianapolis, IN: Hackett.

Pellegrino, E. (1985) The virtuous physician, and the ethics of medicine. In Virtue and Medicine (ed. E. Shelp), pp. 237-255. Dordrecht: Reidel.

Plato (edition 199I) Meno. In Greek Philosophy: Thales to Aristotle (3rd edn) (ed. R. Allen), pp. II0-14I. New York: Free Press.

Radden, J. (2002) Notes towards a professional ethics for psychiatry. Australian and New Zealand Journal of Psychiatry, 36, 52-59.

Ross, W. D. (1930) The Right and the Good. Oxford: Clarendon.

Royal Australian and New Zealand College of Psychiatrists (2004) Code of Ethics (3rd edn). Melbourne: Royal Australian and New Zealand College of Psychiatrists.

Veatch, R. (1998) The place of care in ethical theory. Journal of Medicine and Philosophy, 23, 210-224.

Williams, W. C. (1984) The use of force. In The Doctor Stories (ed. R. Coles), pp. 56-60. New York: New Directions. 